\title{
PENERAPAN MODEL ARIMA UNTUK PERAMALAN JUMLAH KLAIM PROGRAM JAMINAN HARI TUA PADA BPJS KETENAGAKERJAAN KOTA LANGSA
}

\section{Application of ARIMA Models for Forecasting the Amount of Claims of The Old Day Guarantee Program in Labor BPJS in Kota Langsa}

\author{
Fazrina Saumi $^{1 *}$, Rizki Amalia ${ }^{2}$ \\ ${ }^{1}$ Prodi Matematika, Fakultas Teknik, Universitas Samudra \\ ${ }^{2}$ Prodi Pendidikan Matematika, FKIP, Universitas Samudra \\ Jl. Meurandeh, Langsa Lama, Kota Langsa, Aceh, 24354, Indonesia \\ e-mail:1*fazrinasaumi@unsam.ac.id;2rizkiamalia@unsam.ac.id \\ Corresponding author*
}

\begin{abstract}
Abstrak
BPJS Ketenagakerjaan Langsa adalah Badan Hukum Publik yang dibentuk untuk menyelenggarakan program jaminan sosial bagi pekerja. Program tersebut dikelola oleh PT. JAMSOSTEK dengan 4 program salah satunya adalah program Jaminan Hari Tua (JHT). Program JHT adalah program jangka panjang yang diberikan secara berkala sekaligus sebelum Peserta memasuki masa pensiun. Penelitian ini bertujuan untuk jumlah klaim peserta BPJS Ketenagakerjaan pada program JHT dengan model ARIMA, melalui peramalan tersebut BPJS dapat meningkat pelayanan dengan jumlah klaim dari tahun ke tahun agar tingkat kepuasan peserta program JHT terjamin. Pengolahan data menggunakan software MINITAB 18 dengan langkah awal stasioneritas data, identikasi model tentatif $(p, d, q)$ estimasi parameter model, uji diagnosis, dan terakhir model digunakan untuk peramalan. Model ARIMA yang didapat adalah ARIMA $(4,1,2)$ dengan nilai MAPE $6,87 \%$ yang menunjukkan hasil peramalan sangat baik. Hasil peramalan jumlah klaim program JHT pada BPJS Ketenagakerjaan periode Agustus 2019 sampai Desember 2019 masing-masing sebanyak 444, 403, 419, 336, 404 orang. Berdasarkan hasil ramalan tersebut bahwa jumlah klaim program JHT mengalami fluktuasi, hal tersebut menunjukkan bahwa BPJS Ketenagakerjaan Kota Langsa perlu meningkat pelayan pada Program JHT tersebut.
\end{abstract}

Kata Kunci : Peramalan, Model ARIMA, Program Jaminan Hari Tua (JHT), BPJS Ketenagakerjaan.

\begin{abstract}
Social Security (BPJS Ketenagakerjaan) in Langsa is a Public Legal established to organize social security programs for workers. The program is managed by PT. JAMSOSTEK with 4 programs one of which is JHT (Jaminan Hari Tua / Old Age Protection). JHT program is a long-term program that is given periodically at once before participant enter retirment. This research aims to increase the number of claims of BPJS Ketenagakerjaan participants in JHT program with ARIMA model, through the forecast BPJS can increase service with the number of claims from year to year so that the satisfaction level of JHT program participants is guaranteed. Data processing uses MINITAB 18 software with data stationary initial steps, tentavie model identically $(p, d, q)$ model parameter estimation, diagnostic test, and last model used for forecasting. The ARIMA model obtained is ARIMA $(4,1,2)$ with a MAPE value of $6.87 \%$ which shows excellent forecasting results. The result forecast the number of JHT program claims in BPJS Ketenagakerjaan period August 2019 to December 2019 as may as 444, 403, 419, 336, 404 people, respectively. Based on the results of the forecast, especially that the number of JHT program claims fluctuated, this indicates that BJPS Ketenagakerjaan in Langsa needs to increase the equivalent service for the JHT program.
\end{abstract}

Keywords: Forecasting, ARIMA Model, Jaminan Hari Tua (JHT) Program, BPJS Ketenagakerjaan. 


\section{PENDAHULUAN}

BPJS Ketenagakerjaan adalah Badan Hukum Publik yang dibentuk untuk menyelenggarakan program jaminan sosial bagi pekerja, BJPS Ketenagakerjaan memiki 4 program yang dikelola oleh PT. JAMSOSTEK, yaitu Jaminan Hari Tua (JHT), Jaminan Kecelakaan Kerja (JKK),Jaminan Pensiun (JP) dan Jaminan Kematian $(\mathrm{JKm})$ [1]. Penyelenggaraan Jaminan Sosial Bidang Ketenagakerjaan berdasarkan Undang-Undang Nomor 24 Tahun 2011 tentang Badan Penyelenggara Jaminan Sosial dalam Pasal 6 ayat (2) sejak 1 Juli 2015 [2].

BPJS Ketenagakerjaan memiki program perlindungan dasar yang menjamin masa depan pekerja, termasuk perlindungan dari ketidakpastian risiko sosial dan ekonomi yang mungkin saja terjadi, seperti risiko kecelakaan kerja, sakit, kematian dan masa tidak bekerja serta pensiun. Salah satu program yang memiki tingkat klaim terbanyak adalah JHT. Program JHT adalah program jangka panjang yang diberikan secara berkala sekaligus sebelum peserta memasuki masa pensiun, yang dapat juga diterima oleh janda/duda, anak atau ahli waris peserta yang sah apabila peserta meninggal dunia.

Iuran/premi di BPJS Ketenagakerjaan sangat rendah, dan terjangkau dengan kantong pekerja yang mengambil program JHT sebagai tabungan hari tua dan memiliki manfaat yang sangat bagus. JHT di berikan kepada tenaga kerja telah mencapai usia pensiun 56 tahun, mengalami cacat total, meninggal dunia, mengundurkan diri dan terkena PHK, serta meninggalkan Negara Republik Indonesia untuk selama-lamanya.

Program JHT BPJS didasari oleh prinsip asuransi atau tabungan, dimana hal ini menjadi tolak ukur untuk BPJS untuk meningkatkan pelayanan pada program-program yang ada di BPJS khususnya program JHT yang menjadi manfaat pada pekerja yang akan pensiun untuk menghadapi masa tuanya, dikarenakan pelayanan asuransi tidak hanya ada di BPJS namun banyak perusahaan asuransi yang melayani asuransi dengan tawaran-tawaran untuk menarik peserta agar peserta tertarik pada asuransi tersebut. Permasalahan tersebut merupakan hal yang harus diperhatikan oleh BPJS untuk meningkatkan pelayanan pada peserta agar tingkat kepuasan peserta terjamin. Peningkatan kepuasan pada peserta BPJS diketahui jumlah peserta BPJS dan jumlah klaim pada program tersebut. Untuk melihat tingkat klaim pada program JHT di BPJS dapat dilakukan dengan peramalan, oleh karena itu pihak BPJS dapat melihat tingkat kepuasan dari peserta BPJS dari jumlah peserta yang mengklaim dari tahun ke tahun. Dikarenakan perusahaan asuransi saat ini diwarnai persaingan yang ketat dimana terjadi persaingan untuk mempertahankan peserta asuransi dan terus meningkatkan kegiatan usahanya, dengan melihat tingkat jumlah klaim pada program JHT dapat mengukur kepuasan peserta program JHT memilih BPJS Ketenagakerjaan.

Peramalan bertujuan memperbaikan dan menggunakan data masa lalu memperbaiki kekurangan masa lalu [3]. [4] menambahkan peramalan merupakan proses atau metode dalam meramal suatu peristiwa yang akan terjadi pada masa datang dengan mendasarkan diri pada variabel-variabel tertentu. Peramalan merupakan cara untuk mengambil keputusan sehingga dapat merencanakan untuk manajemen yang baik kedepannya [5], hal ini sependapat dengan [6] peramalan dapat mengubah masa depan dan mengatur yang strategis. Peramalan yang dilakukan dengan menggunakan berbagai informasi atau data yang diperoleh dalam periode waktu yang cukup panjang atau dapat disebut dengan data time series, dan data tersebut dapat digunakan untuk mengetahui bagaimana proses suatu estimasi dan hasil peramalan dengan baik melalui peramalan time series [7].

Data yang diperoleh dianalisis untuk menentukan pola data masa lalu yang telah dikumpulkan dengan menggunakan model ARIMA (Autoregressive Integrated Moving Average) yang dapat meramalkan peramalan jangka pendek untuk data yang tidak stasioner [8]. Model deret waktu seperti ARIMA berupaya untuk meramalkan kondisi masa yang akan datang dengan menggunakan data historis dan memprediksi masa yang akan datang [9]. Estimasi hasil ARIMA dalam beberapa hasil penelitian cocok digunakan untuk memprediksi variabel yang sangat sensitif oleh perubahan jangka pendek [10].Model ARIMA adalah model yang menggunakan variabel dependen dan mengabaikan variabel independen untuk menghasilkan peramalan jangka pendek yang akurat [11]. 


\section{METODE PENELITIAN}

\section{Langkah 1: Studi Literatur}

Studi literatur yang dilakukan penulis adalah dengan mempelajari pembahasan mengenai peramalan dan metode peramalan dengan model ARIMA yang didapat dari buku-buku, jurnal, artikel dan media internet yang berguna dalam menyelesaikan masalah pada penelitian ini. Model Autoregressive Integrated Moving Average (ARIMA) merupakan model ARMA (p,q) non stasioner, dengan I adalah differencing (d). Data yang digunakan pada model ARIMA adalah data yang tidak stasioner, berbeda dengan AR dan MA yang menggunakan data yang stasioner. Pada model ARMA $(\mathrm{p}, \mathrm{q})$ non stasioner, proses pembedaan dilakukan agar data menjadi stasioner. Setelah model ARMA mengalami proses pembedaan sebanyak d kali hingga stasioner, maka model ARMA (p,q) menjadi model ARIMA (p,d,q).

\section{Langkah 2: Pengumpulan Data}

Data yang digunakan pada penelitian ini adalah pengumpulan data yang diperoleh dari Kantor BPJS Ketenagakerjaan Langsa, terkait jumlah data klaim pada BPJS Ketenegakerjaan Langsa khususnya program Jaminan Hari Tua (JHT) periode Januari 2014 sampai Juli 2019.

\section{Langkah 3: Pengolahan Data}

Tahap-tahap pengolahan data untuk peramalan jumlah klaim program JHT pada BPJS Ketenagakerjaan menggunakan model ARIMA dengan bantuan software MINITAB 18, yaitu:

1. Pemeriksaan kestasioneran data

Data dikatakan stasioner jika kesetimbangan di sekitar nilai rata-rata konstan dan varian disekitar ratarata konstan pada pola data selama waktu tertentu [12]. Kestasioneran data dibagi menjadi dua yaitu, stasioner dalam varian dan stasioner dalam mean. Kestasioneran dalam varian dilihat dari nilai rounded value $($ Lambda $)=1$, yang terdapat pada plot tranformasi Box-Cox. Sedangkan kestasioneran dalam mean dilihat dari rata-ratanya konstan (tidak terdapat pola trend)), untuk menstasionerkannya dapat melakukan tahap differencing (pembedaan). Stasioner dalam mean juga dapat dilihat dari plot ACF dan PACF yang dihasilkan, jika lag pada ACF atau PACF Cut Off menuju 0.

2. Identifikasi model dalam ARIMA. Melalui plot ACF dan PACF kita dapat menentukan model ARIMA yang bisa digunakan dalam peramalan dengan memperhatikan perilaku-perilaku Fungsi ACF dan PACF [13].

3. Penentuan Parameter $p, d$ dan $q$ dalam ARIMA.

Plot ACF dan PACF yang telah stasioner daat menentukan nilai $p$ untuk AR yang didapat dari plot PACF, dan nilai $q$ untuk MA didapat dari plot ACF. Sedangkan nilai $d$ merupakan banyaknya data melakukan differencing.

4. Tahap pengujian kesesuaian model atau diagnosa model.

Tahap ini dilakukan untuk melihat apakah model $p, d, q$ yang didapat sesuai untuk menentukan persamaan model ARIMA. Uji diagnosa model dilakukan dengan uji asumsi residual white nose yang merupakan proses pengujian tidak terdapat korelasi dalam deret residual [14], uji asumsi distribusi normal dan uji overfitting yang dilakukan jika model yang sudah ditentukan terdapat salah satu pengujian yang tidak sesuai, maka dilakukan tahap uji overfitting dengan melihat nilai error yang terkecil dari model ARIMA yang didapat untuk mendapatkan model ARIMA terbaik. Bentuk umum dari model ARIMA $(p, d, q)$ dengan pemisalan untuk $d=1$ [15] adalah:

$$
\begin{aligned}
& Y_{t}-Y_{t-1} \\
& =\varphi_{1}\left(Y_{t-1}-Y_{t-2}+\varphi_{2}\left(Y_{t-2}\right.\right. \\
& \left.-Y_{t-3}\right)+\cdots+\varphi_{p}\left(Y_{t-p}\right. \\
& \left.-Y_{t-p-1}\right)+e_{t}-\theta_{1} e_{t-1} \\
& \quad-\theta_{2} e_{t-2}-\cdots-\theta_{q} e_{t-q}
\end{aligned}
$$


5. Penentuan persamaan model ARIMA. Koefisien-koefisien yang digunakan dihasilkan dari hasil analisis parameter model ARIMA dengan MAPE yang terkecil. nilai MAPE kurang dari 20\% untuk hasil yang bagus atau kurang dari $10 \%$ untuk hasil yang sangat baik.

Peramalan jumlah klaim program JHT di BPJS Ketenagakerjaan periode Agustus - Desember 2019. Langkah selanjutnya adalah dengan menggunakan model terbaik untuk peramalan. Jika model terbaik telah ditetapkan, model itu siap digunakan untuk peramalan jumlah klaim BPJS Ketenagakerjaan program JHT.

\section{HASIL DAN PEMBAHASAN}

Data yang digunakan pada penelitian ini adalah jumlah data klaim program JHT di BPJS Ketenagakerjaan Langsa pada periode Januari 2014 sampai Juli 2019, yaitu:

Tabel 1. Jumlah Klaim JHT periode 2014 sampai Juli 2019

\begin{tabular}{|c|c|c|c|c|c|}
\hline Periode & $\begin{array}{c}\text { Jumlah Klaim } \\
\text { (Orang) }\end{array}$ & Periode & $\begin{array}{c}\text { Jumlah Klaim } \\
\text { (Orang) }\end{array}$ & Periode & $\begin{array}{c}\text { Jumlah Klaim } \\
\text { (Orang) }\end{array}$ \\
\hline Jan-2014 & 157 & & & & \\
\hline Feb-2014 & 160 & Des-2015 & 366 & Okt-2017 & 288 \\
\hline Mar-2014 & 235 & Jan-2016 & 429 & Nov-2017 & 278 \\
\hline Apr-2014 & 165 & Feb-2016 & 367 & Des-2017 & 146 \\
\hline Mei-2014 & 129 & Mar-2016 & 264 & Jan-2018 & 176 \\
\hline Jun-2014 & 247 & Apr-2016 & 278 & Feb-2018 & 336 \\
\hline Juli-2014 & 392 & Mei-2016 & 369 & Mar-2018 & 194 \\
\hline Aug-2014 & 214 & Jun-2016 & 296 & Apr-2018 & 110 \\
\hline Sep-2014 & 279 & Juli-2016 & 135 & Mei-2018 & 432 \\
\hline Okt-2014 & 255 & Aug-2016 & 213 & Jun-2018 & 230 \\
\hline Nov-2014 & 161 & Sep-2016 & 346 & Juli-2018 & 289 \\
\hline Des-2014 & 178 & Okt-2016 & 255 & Aug-2018 & 390 \\
\hline Jan-2015 & 113 & Nov-2016 & 231 & Sep-2018 & 235 \\
\hline Feb-2015 & 140 & Des-2016 & 172 & Okt-2018 & 393 \\
\hline Mar-2015 & 120 & Jan-2017 & 280 & Nov-2018 & 340 \\
\hline Apr-2015 & 133 & Feb-2017 & 359 & Des-2018 & 305 \\
\hline Mei-2015 & 129 & Mar-2017 & 262 & Jan-2019 & 443 \\
\hline Jun-2015 & 167 & Apr-2017 & 179 & Feb-2019 & 290 \\
\hline Juli-2015 & 142 & Mei-2017 & 264 & Mar-2019 & 253 \\
\hline Aug-2015 & 94 & Jun-2017 & 191 & Apr-2019 & 292 \\
\hline Sep-2015 & 765 & Juli-2017 & 199 & Mei-2019 & 643 \\
\hline Okt-2015 & 451 & Aug-2017 & 266 & Jun-2019 & 257 \\
\hline Nov-2015 & 421 & Sep-2017 & 164 & Juli-2019 & 333 \\
\hline
\end{tabular}

Sumber Data: BPJS Ketenagakerjaan Kota Langsa 


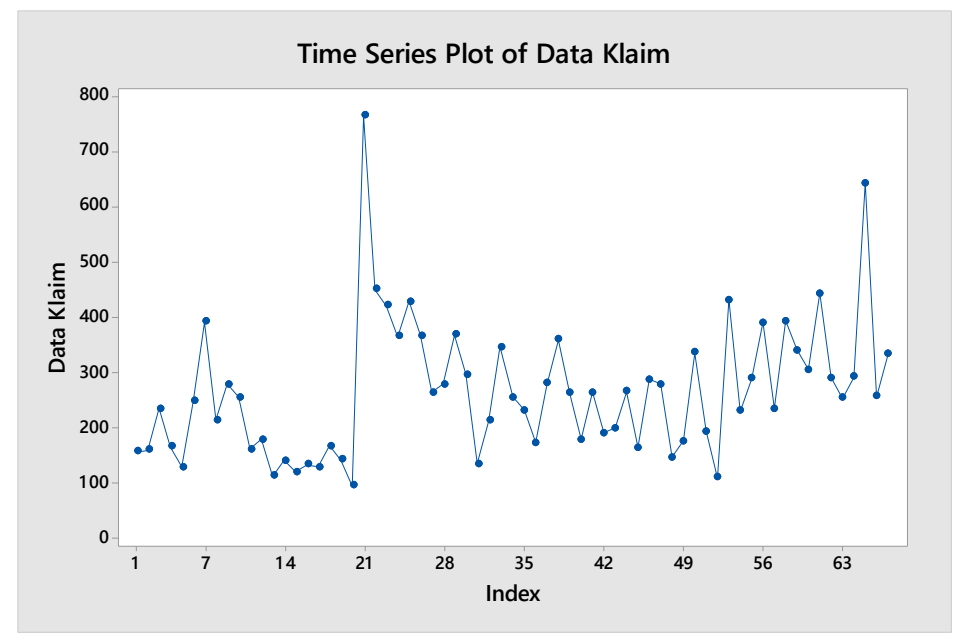

Gambar 1. Plot Times Series Data Klaim JHT

Berdasarkan Gambar 1, dapat dilihat bahwa jumlah klaim JHT pada BPJS Ketenagakerjaan mengalami fluktuasi, dimana jumlah klaim mengalami kenaikan dan penurunan, untuk jumlah klaim terendah pada bulan Augustus 2015 sebanyak 94 orang dan mengalami kenaikan yang cukup tinggi untuk jumlah klaim program JHT yaitu sebanyak 765 pada bulan September 2015. Tidak terdapat unsur musiman pada plot times series diatas dikarenakan naik turunnya pada plot tidak terjadi pada waktu yang sama. Maka model ARIMA dapat digunakan untuk meramalkan jumlah klaim program JHT pada BPJS Ketenagakerjaan.

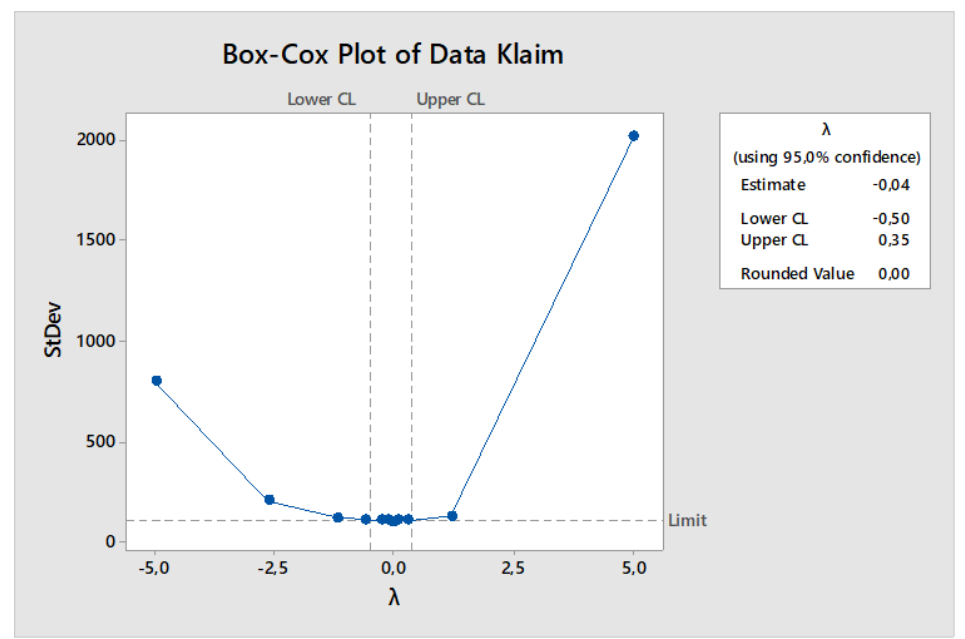

Gambar 2. Box-Cox Tidak Stasioner

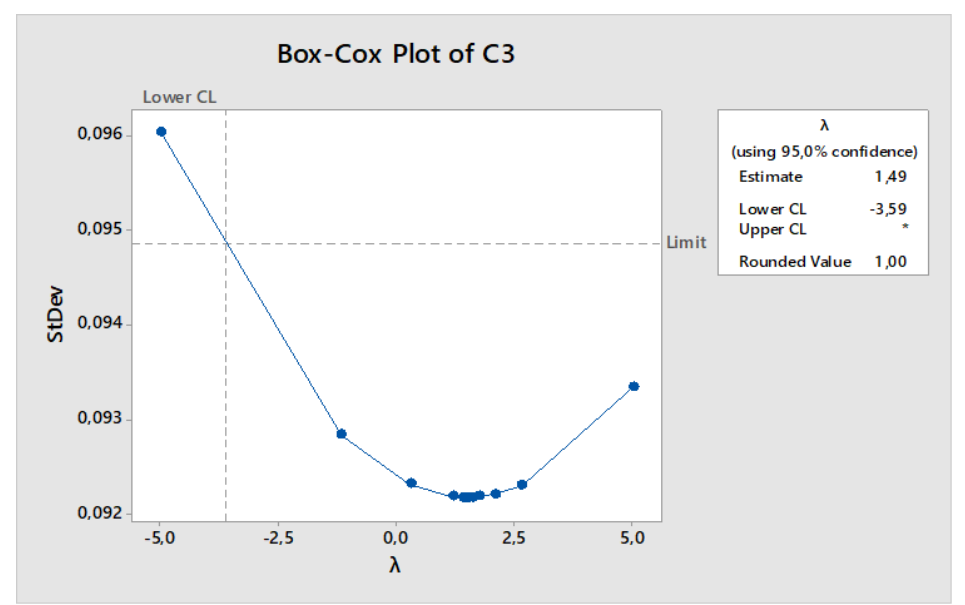

Gambar 3. Box-Cox Stasioner

Gambar 3, menunjukkan bahwa plot Box-Cox jumlah klaim BPJS Ketenagakerjaan untuk program JHT sudah stasioner setelah transformasi sebanyak 3 kali. Tranformasi Box-Cox digunakan untuk melakukan 
tranformasi jika data belum stasioner dalam variansi dikarenakan nilai rounded value kurang dari 1, dimana rounded value dikatakan baik jika nilainya adalah 1.

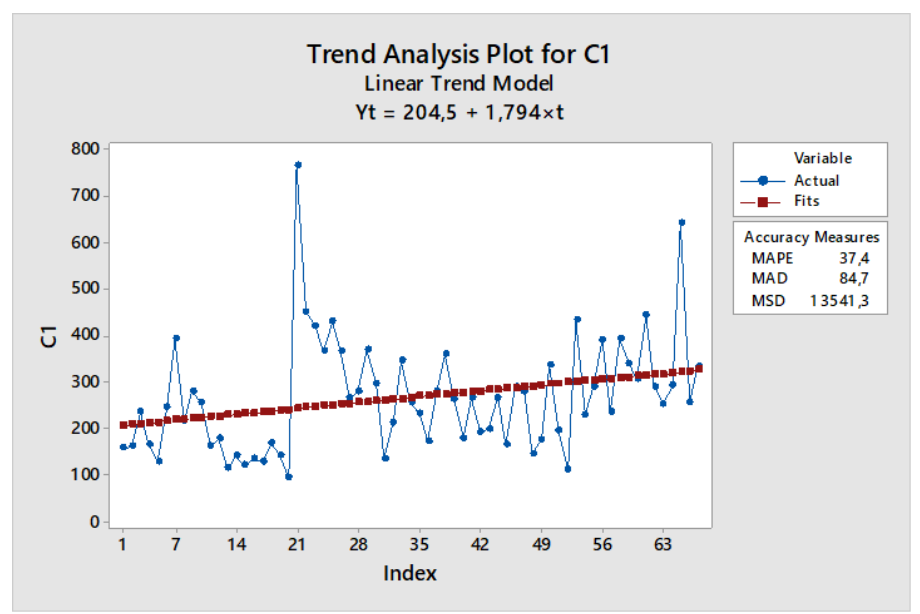

Gambar 4. Trend Analysis Tidak Stasioner

Plot trend analysis diatas menunjukkan bahwa data klaim JHT tidak stasioner terdapat mean dan terlebih dahulu harus ke tahap differencing agar data stasioner dan model yang dihasilkan dapat digunakan untuk peramalan. Pada plot trend diatas menggunakan data acuan jumlah klaim program JHT BPJS Ketenagakerjaan.

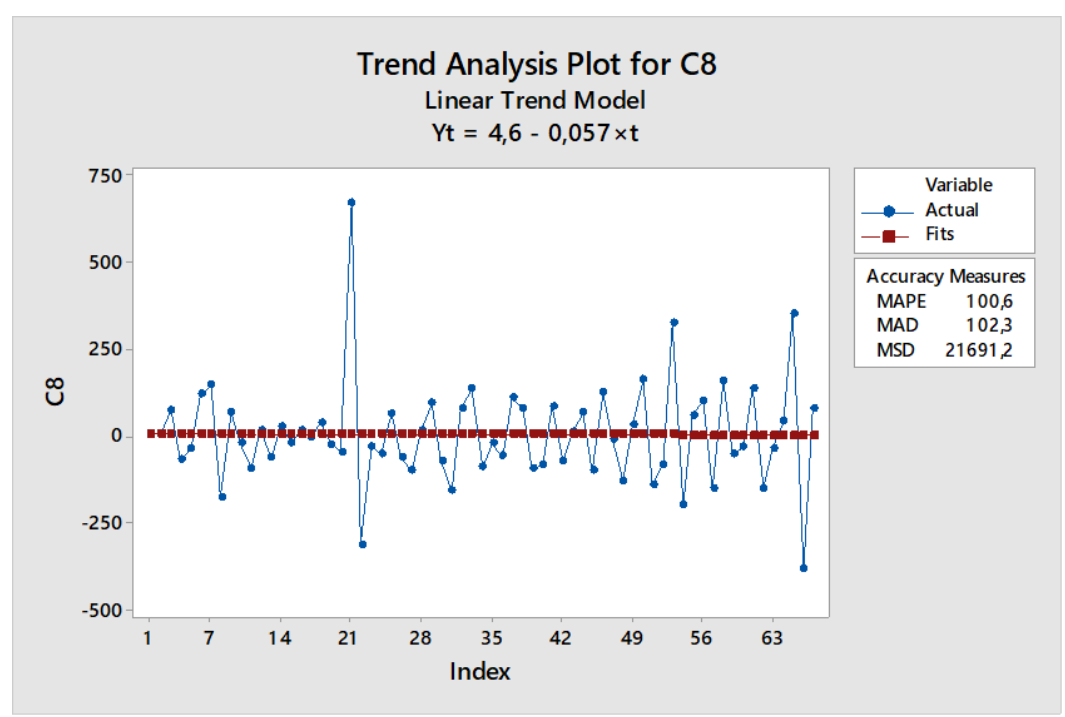

Gambar 5. Trend Analysis Stasioner

Setelah melakukan tahap differencing sebanyak 1 kali data jumlah klaim JHT telah stasioner terhadap mean. Kestasioneran data jumlah klaim JHT dapat juga dilihat melalui plot ACF dan PACF, sebagai berikut: 


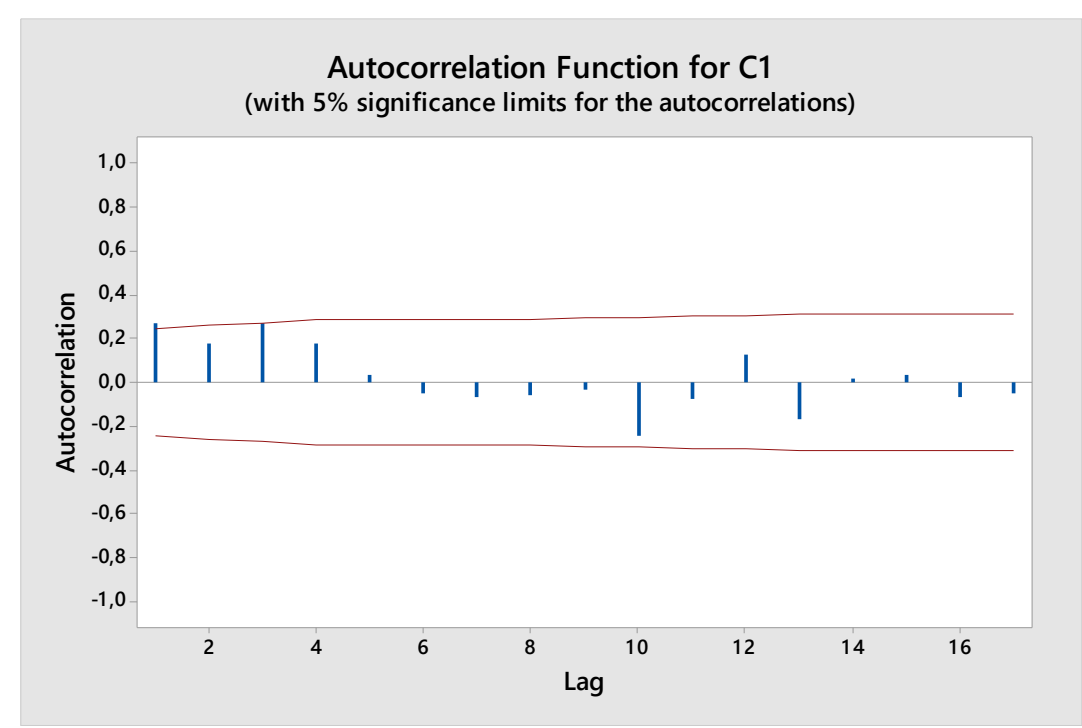

Gambar 6. Plot ACF tidak Stasioner

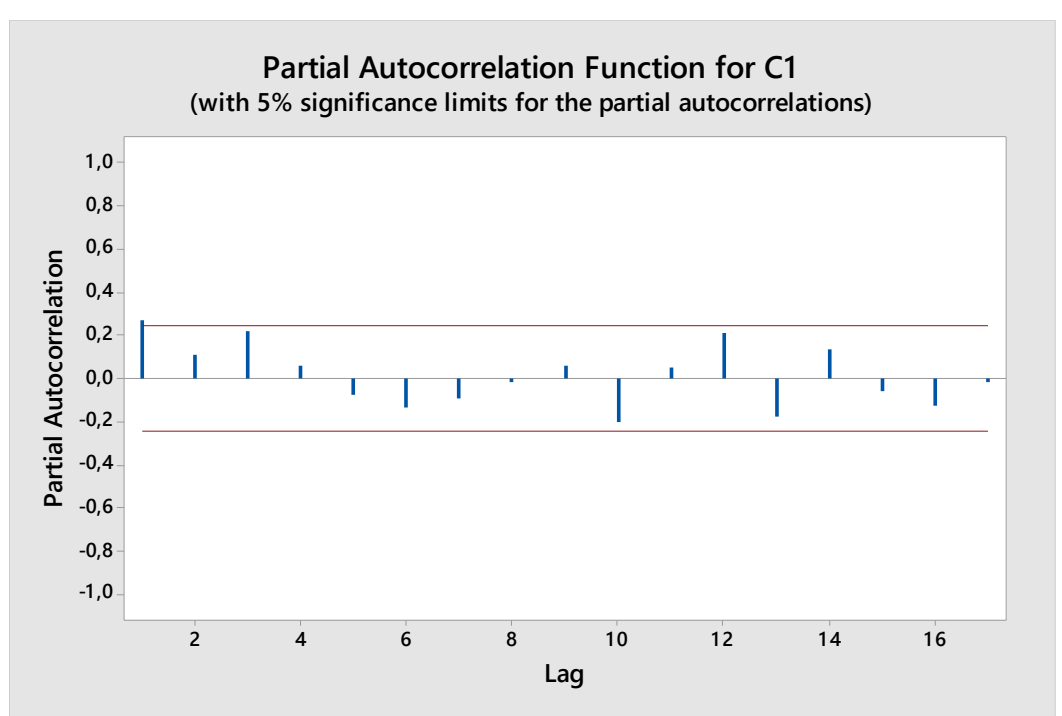

Gambar 7. Plot PACF tidak stasioner

Tahap differencing yang dilakukan pada plot trend analysis secara otomatis dapat menstasionerkan plot ACF dan PACF diatas, dengan hasil stasioner plot ACF dan PACF sebagai berikut:

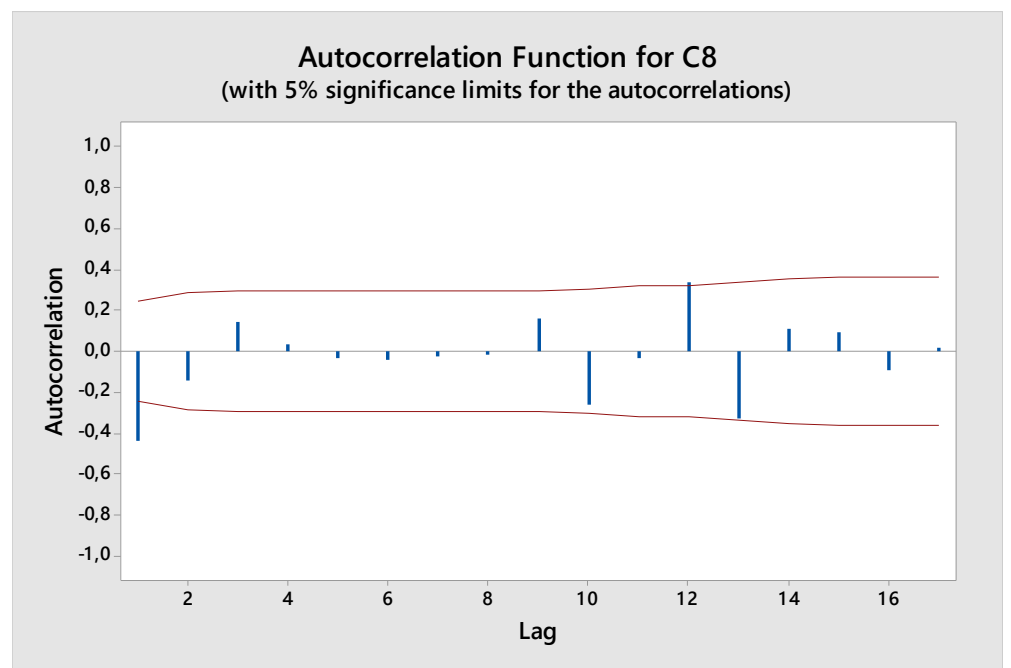

Gambar 8. Plot ACF Stasioner 


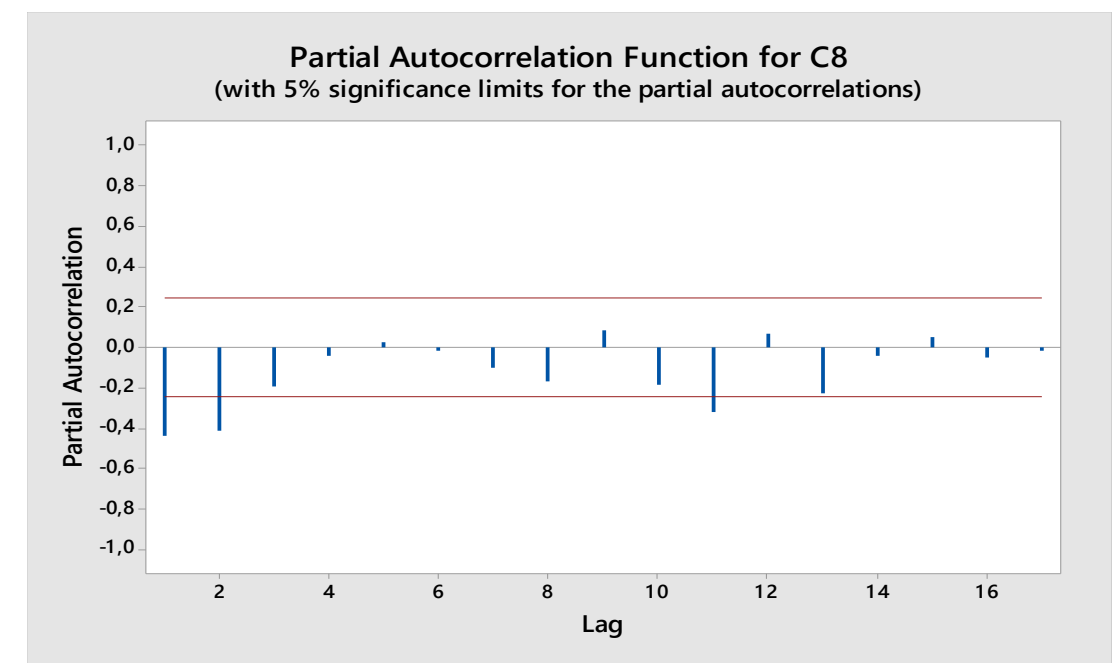

Gambar 9. Plot PACF Stasioner

Tabel 2. Estimasi Model ARIMA

\begin{tabular}{lll}
\hline \multicolumn{1}{c}{ ACF } & \multicolumn{1}{c}{ PACF } & \multicolumn{1}{c}{ MODEL } \\
\hline Dies Down & Cut Off pada lag 1,2,3,4 & $p=1, p=2, p=3$, atau $p=4$ \\
\hline Cut Off pada lag ke 1 & Dies Down & $q=1$ \\
\hline
\end{tabular}

Melalui kedua plot ACF dan PACF yang telah stasioner dapat menghasilkan estimasi parameter untuk model AR $(p)$ dan MA $(q)$, yaitu untuk nilai $p$ adalah $1,2,3$ dan 4 dan nilai $q$ adalah 1 dan 2 . Untuk estimasi model ARIMA adalah dengan model dugaan sementara yaitu ARIMA $(1,1,1)$, ARIMA $(2,1,1)$, ARIMA $(3,1,1)$, ARIMA $(4,1,1)$, ARIMA $(1,1,2)$, ARIMA $(2,1,2)$, ARIMA $(3,1,2)$, ARIMA $(4,1,2)$. Dengan bantuan MINITAB 18 untuk melihat model ARIMA signifikan yang baik digunakan untuk peramalan hanya ARIMA $(4,1,2)$, dimana hanya model ARIMA $(4,1,2)$ yang memiliki nilai P-Value $<0,05$. Model yang signifikan hanya ARIMA $(4,1,2)$ maka model tersebut tidak melalui tahap pengujian asumsi residual white noise dan asumsi distribusi normal karena tidak ada pemilihan model terbaik melalui pengujian tersebut dikarenakan hanya model ARIMA $(4,1,2)$ yang signifikan. Persamaan model yang diperoleh adalah:

$$
\begin{gathered}
Y_{t}=Y_{t-1}-1,178\left(Y_{t-1}-Y_{t-2}\right)-1,741\left(Y_{t-2}-Y_{t-3}\right)-1,008\left(Y_{t-3}-Y_{t-4}\right)-0,566\left(Y_{t-4}-Y_{t-5}\right. \\
+e_{t}+0,508 e_{t-1}+0,949 e_{t-2}
\end{gathered}
$$

Berdasarkan model ARIMA yang sudah ditentukan yaitu ARIMA $(4,1,2)$ dapat ditentukan hasil peramalan jumlah klaimprogram JHT di BPJS Ketenagakerjaan untuk bulan Agustus-Desember 2019 dengan bantuan MINITAB 18, yaitu:

Tabel 3. Hasil Peramalan

\begin{tabular}{cc}
\hline Periode & Jumlah Klaim (Orang) \\
\hline Aug-2019 & 444 \\
\hline Sep-2019 & 403 \\
\hline Okt-2019 & 419 \\
\hline Nov-2019 & 336 \\
\hline Des-2019 & 404 \\
\hline
\end{tabular}

Hasil dari Tabel 3 merupakan hasil peramalan dari jumlah klaim program JHT di BPJS Ketenagakerjaan dengan nilai persentase kesalahan MAPE sebesar 6,87\%. Dengan hasil persentase tersebut menyatakan bahwa hasil peramalan sangat baik, karena nilai MAPE kurang dari $20 \%$ dan kecocokan model peramalan cukup akurat.

\section{KESIMPULAN}

Berdasarkan hasil pembahasan sebelumnya kesimpulan yang diperoleh adalah adanya kenaikan dan penurunan dari jumlah klaim program JHT di BPJS Ketenagakerjaan dari periode Agustus 2019 sampai 
Desember 2019. Model ARIMA yang digunakan adalah ARIMA $(4,1,2)$ dengan MAPE sebesar 6,87\% untuk hasil peramalan yang baik karena kecilnya persentase kesalahan dari hasil peramalan.

\section{UCAPAN TERIMA KASIH}

Terima kasih kepada BPJS Ketenagakerjaan Kota Langsa dan pihak lainnya yang telah membantu dalam penyelesaian artikel penelitian ini.

\section{DAFTAR PUSTAKA}

[1] Husni, Lalu. Pengantar Hukum Ketenagakerjaan. PT. Raja Grafindo Persada. Jakarta, 2014.

[2] Badikenita, Rekson Silaban. Perluasan Kepesertaan Bpu Bpjs Ketenagakerjaan Melalui Strategi Marketing Mix Dan Regulasi. Jurnal Institut BPJS Ketenagakerjaan. 2, 1-50, 2017.

[3] Fattah, J., Latifa, E., Zineb, A., Haj, E, M, dan Abdeslam, L. Forecasting Of Demand Using ARIMA Model. Internationa Journal Of Engineering Business Management. 10, 1-9. 2018.

[4] Awat, J. Napa. Metode Peramalan Kantitatif. Yogyakarta: Liberty, 1990.

[5] Unggara, I., Aina, M., Anny, K, S. Optimization Of ARIMA Forecating Model Using Firefly Algorithm. IJCCS. 13 (2). 2019.

[6] Bakar, N, A., Sofian, R. ARIMA Model ForForecating Crytocurrency Exchange Rate In higt Volatility Environment: A New Insight Of Bitcoin Transaction. IJAERS. 4(11). 2017.

[7] Hartati. Penggunaan Metode ARIMA Dalam Meramal Pergerakan Inflasi. Jurnal Matematika, Sains dan Teknologi. 18(1), 1-10, 2017.

[8] Salwa, N., Nidya, T., Ridha, A., dan Aja, F.Z. Peramalan Harga Bitcoin Menggunakan Metode ARIMA (Autoregressive Integrated Moving Average). Journal of Data Analysis.1(1), 21-31, 2018.

[9] Hasniah, Sri, W., dan Desi, Y. Penerapan Metode ARIMA Ensembel pada Peramalan (Studi Kasus: Inflasi di Indonesia). Jurnal EKSPONENSIAL. 7(1), 85-94, 2016.

[10] Susilowati, F. Metode ARIMA untuk Meramalkan Jumlah Uang Beredar (M2) Di Indonesia. Journal Of Business Theory and Implementation. 6 (1), 2015

[11] Salwa, N., Nidya, T., Ridha, A., Aja, F, Z. Peramalan Harga Bitcoin Menggunakan Metode ARIMA. Jurnal Of data Analysis. 1(1). 2018.

[12] Makridakis S, dan Wheelwright S.C. Metode-Metode Peramalan untuk Manajemen. Erlangga.Jakart, 1991.

[13] Mendome, K., Nelson, N., dan John, K. Peramalan Model ARIMA dalam Memprediksi Jumlah Tindak Kriminalitas di Wilayah POLRESTA Manado Provinsi Sulawesi Utara. JURNAL MIPA UNSRAT. 5(2), 113-116, 2016.

[14] Wei, W.W.S. Time Series Analysis: Univariate and Multivariate Methods. Pearson Education, Inc. California, 2006.

[15] Cryer, J.D., dan Kung-Sik Chan (Ed 2). Time Series Analysis With Applications in R. Spinger Scine+Business Media, LCC. New York, 2008. 
